\title{
An Enzyme Histochemical Study of Cerebral Arteriosclerosis *
}

\author{
(With some data on the pathogenesis of periarterial scars)
}

\author{
By \\ REINHARD L. FRIEDE
}

With 12 Figures in the Text ( 1 in Color)

(Received January 30, 1962)

\section{Introduction}

This paper describes the histopathology of cerebral arteriosclerosis as reflected by histochemical data on the oxidative enzymes DPN-diaphorase and succinic dehydrogenase, the hydrolytic enzymes acid and alkaline phosphatase, and data on mitochondria. It represents an effort to apply mappings of the normal distribution of enzyme activity in the human brain to neuropathology. The distribution of DPN-diaphorase in fiber tracts (FRIEDE 1961) and measurements of the gradations of this enzyme among most nuclei of the human brain are now available as a baseline on normal chemoarchitecture (FrIEde and Fleming 1962). Likewise, the distribution of four oxidative enzymes and capillarization in the brain stem of the cat has been mapped in a histochemical atlas (FRIEDE 1961). Other studies applied these data to the investigation of multiple sclerosis (FrIEDE 1961) and Alzheimer's disease (FRIEDE and MAGEE 1962) providing much new information.

It is recognized that investigation of only four of the hundreds of enzymes working in the tissue represents a fragment of what can be studied. Histochemical methods are available for at least 45 enzymes. However, the application of these techniques to neuropathology must be preceded by knowledge of the normal chemoarchitecture. Such knowledge is indispensable for histochemical studies of pathological material just as neuroanatomy is indispensable for conventional neuropathology.

\section{Material and Methods}

The data described in the following were obtained from several cases of cerebral arteriosclerosis, selected, for optimal enzyme histochemical conditions, from the large postmortem material of the Laboratory of Neuropathology of the University of Michigan. In each case extensive series were cut, using enzyme histochemical methods, conventional stains, and sometimes silver impregnation in adjacent sections from the same blocks. Further correlation of histochemical and conventional data was facilitated by combinations of stains, such as counterstaining of enzyme preparations with chrom alum-gallocyanin and with fat stains. The following histochemical techniques were used:

$D P N$-diaphorase. Formalin-fixed material was stored in the refrigerator for one to two days; $30 \mu$ frozen sections were incubated for two hours at $38^{\circ} \mathrm{C}$ in the medium of FARBER, Sterdberg and Dunlap (1956). This technique and that of SCARPelli, Hess and Pearse (1958) were used interchangeably with identical results. Nitro BT was the tetrazolium salt used with both methods. Some sections were dehydrated and mounted in Permount and others were

* This investigation was supported by U.S. Public Health Grant B-3250. 
mounted in glycerin-gel. Selected sections were counterstained with Sudan Black, Fettrot, or chrom alum-gallocyanin.

Succinic dehydrogenase. Frozen sections of unfixed tissue, $60 \mu$ thick, were incubated in the medium of NACHLASS and coworkers (1957) using Nitro BT.

Acid and alkaline phosphatase. Frozen sections of formalin-fixed tissue, $30 \mu$ thick, were stained with the coupling azo dye methods.

Mitochondria were stained with Altmann's anilin-fuchsin and Novelli's technique.

Reliability of the tetrazolium techniques employed. Tetrazolium techniques for DPNdiaphorase and succinic dehydrogenase have been standardized in this laboratory for the routine measurement of gradations of enzymatic activity among regions of the human brain. The procedure involves the extraction of INT-formazan from tissue discs punched from the sections; the amount of formazan formed in the tissue is measured spectrophotometrically. Comparison of data obtained with this method, in addition to comparison with tissue homo. genate assays, indicated that the patterns of oxidative enzymes described below reflected the true distribution of enzymatic activity and were not distorted by such factors as a nonlinear histochemical reaction, changes due to formalin fixation of the tissue, lipid solubility of formazan, absorbtion of tetrazolium salts on proteins, or nonspecific reaction products. Reference is made, in this regard, to FRIEDE and FleMING 1962, and also to a forthcoming publication.

Technique for capillary measurements. The capillarization of cat brain was demonstrated by injection with india ink. Small samples were taken from the cerebral cortex and were cut at $40 \mu$. The samples were oriented carefully so that the axis of arteries was rectangular to the plane of cutting. The sections were mounted with glycerin-gel to avoid tissue shrinkage.

These slides were projected on a screen with an attached polar-coordinate engineering form (12-187). Such forms show equidistant concentric rings and 36 radial subdivisions. The center of the form was centered in a large artery. Any crossing of a capillary with any of the 36 radial subdivisions was marked. The forms were evaluated by counting the number of capillaries and this was expressed as a function of the distance from the center of the artery. A total of 1980 capillaries were counted.

\section{Results \\ A. Histochemistry of Infarction}

Normal Distribution of Oxidative Enzymes. A complete description of the normal distribution of oxidative enzymes in brain tissue exceeds the scope of this article; a few references may help those not familiar with the normal patterns of enzyme distribution. White matter, in general, exhibited less activity than gray matter. DPN-diaphorase has been demonstrated in oligodendroglia cells of white matter and in thick axons. Several types of oligodendroglia cells were distinguished by gradations of enzyme activity. The relative enzyme distribution in glia cells and axons varied greatly among the tracts of the human brain (FRIEDE 1961). Normal astrocytes showed extremely little activity of oxidative enzymes (FRIEDE 1962).

Gray matter exhibited more activity of oxidative enzymes than white matter but there were considerable gradations of activity among individual nuclei. The activity of any given nucleus was fairly constant in the normal adult brain; however, there were definite cytological variations of enzyme distribution among nuclei. In some nuclei, enzyme activity prevailed in the perikarya of nerve cells, and in others it prevailed in the neuropil. The term neuropil, as used in the following, characterized a diffuse distribution of enzymatic activity between the perikarya. It implied localization of enzyme activity in dendrites, synapses, terminal axon branchings, and also possibly in glial processes. The relative contribution of each of these structures to the total enzyme activity of the neuropil could not be determined with light microscope techniques. The neuropil, under 
pathological and developmental conditions, responded like a uniform tissue structure, its behavior being different from that of perikarya.

Enzyme Changes in Incomplete Necrosis. Incomplete tissue necrosis of gray matter was characterized by a decrease or loss of oxidative enzyme activity in the neuropil. Early slight changes were recognizable only by careful comparison

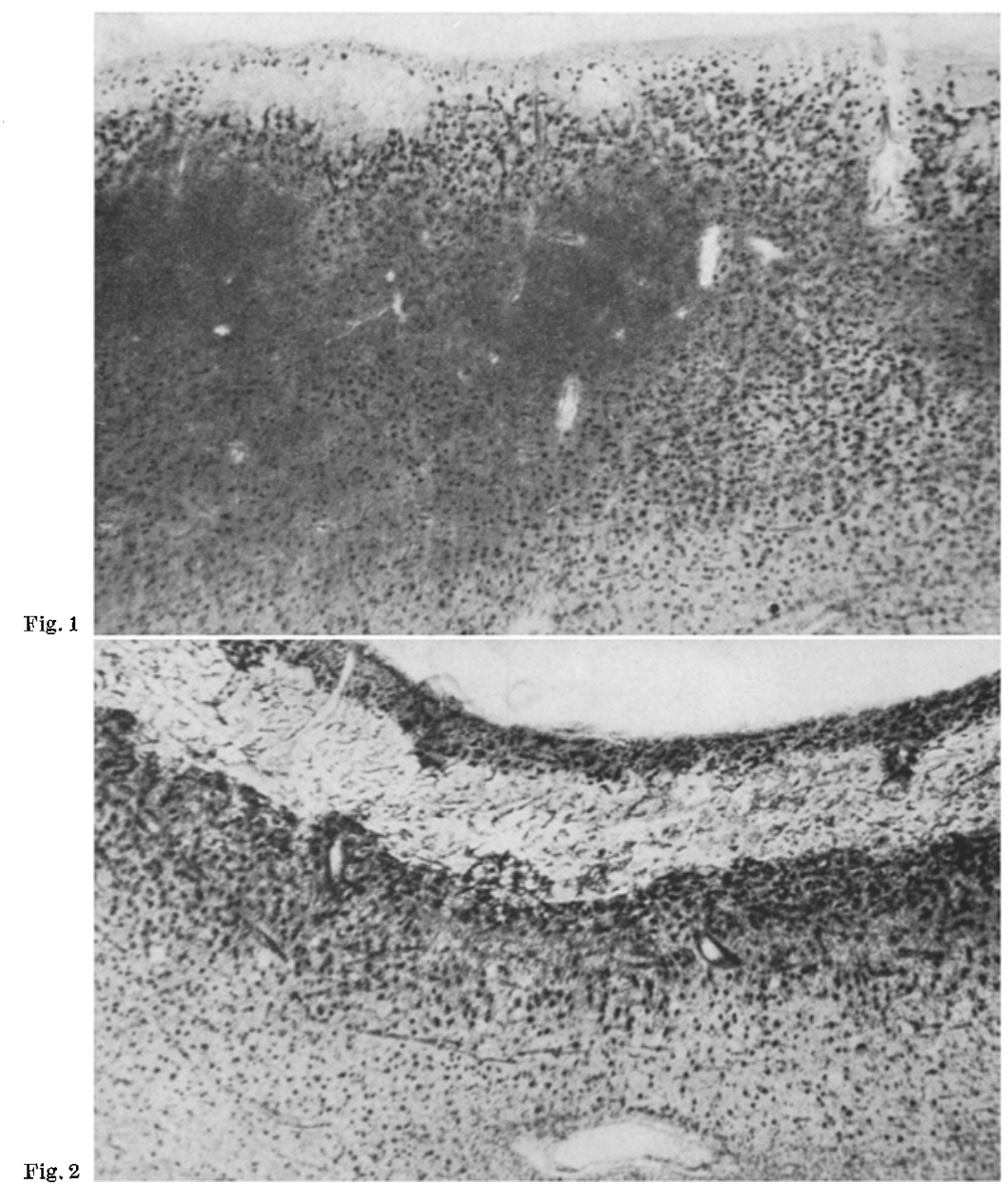

Fig. 1-2. Degrees of cortical damage: Fig. 1 islands of persisting neuropil; Fig. 2 complete necrosis. The heavily stained cells are hypertrophic astrocytes. Note the absence of enzyme activity in the fatty degenerated macrophages in the necrosis in Eig. 2. DPN-diaphorase. $20 \times$

with the normal regional enzyme patterns. Advanced changes were quite conspicuously showing an irregular patchy decrease of the enzyme reaction in the neuropil. Even these conspicuous changes had to be evaluated carefully, since certain thalamic nuclei (e.g., nucl. dorsomedialis) normally showed patchy irregular enzyme patterns. Advanced stages showed only residual islands of neuropil (Fig.1 and 2) with persisting enzyme activity; these were separated from each other by zones of very little or no enzyme activity. Such changes were observed 
in the cerebral cortex and also in putamen, pallidum, thalamus and other nuclei of the brain.

Regions normally characterized by strong enzyme activity in the neuropil and little, or none, in perikarya (e.g. upper cortical laminae) did not show an enzyme reaction in perikarya of nerve cells during any phase of the pathological decrease of activity in the neuropil. Regions which normally showed oxidative enzymes in the perikarya of nerve cells (e.g. fifth and sixth cortical laminae) often suggested some reactive increase of activity following slight damage. This subjective impression, however, could be due to the contrast resulting from the decreased reaction in the neuropil. Severe damage would destroy the nerve cells.

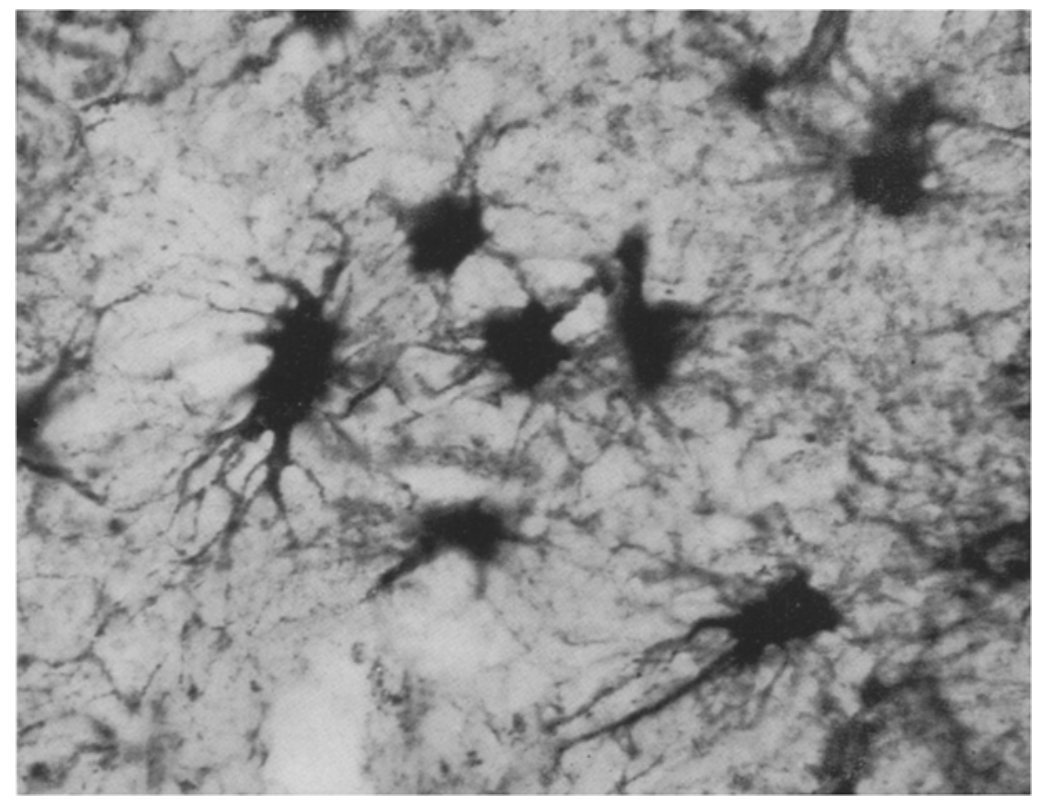

Fig. 3. Hypertrophic astrocytes showing strong DPN-diaphorase activity. $250 \times$

Early Enzyme Changes in Complete Infarction. The early phase of complete tissue necrosis was characterized by a diffuse and complete loss of oxidative enzyme activity. However, the capillaries and larger vessels which persisted in the necrotic tissue, exhibited marked enzyme reaction. The tissue bordering the infarction appeared inert in the early phases. With the demarcation of the infarcted tissue, several histochemical changes appeared in the adjacent tissue, the most conspicuous one being the reaction in astrocytes described as follows.

Histochemistry of Hypertrophic Astrocytes. Normal astrocytes were characterized by very little activity of oxidative enzymes, while an excessively strong reaction was observed in reactive swollen, hypertrophic astrocytes (Fig. 3). The capability to increase enzyme activity seemed to represent a particular feature of astrocytes; reactive astrocytes often were observed intermingled with oligodendroglia cells which had a normal reaction. This selective enzyme change seemed to indicate a specific metabolic reaction of the astrocytes. 
In the later phases of infarction, the necrotic tissue was surrounded by a proliferation of hypertrophic astrocytes (Fig. 4) with very strong enzyme reaction (DPN-diaphorase, succinic dehydrogenase). The astrocytes with increased enzyme activity formed a zone of darker staining which was readily distinguishable to the naked eye (Fig.2). Numerous hypertrophic astrocytes with strong enzyme reaction occupied the persisting upper portion of the molecular layer covering the cortical defect (Fig. 2). The molecular layer exceeded manifold its normal activity.

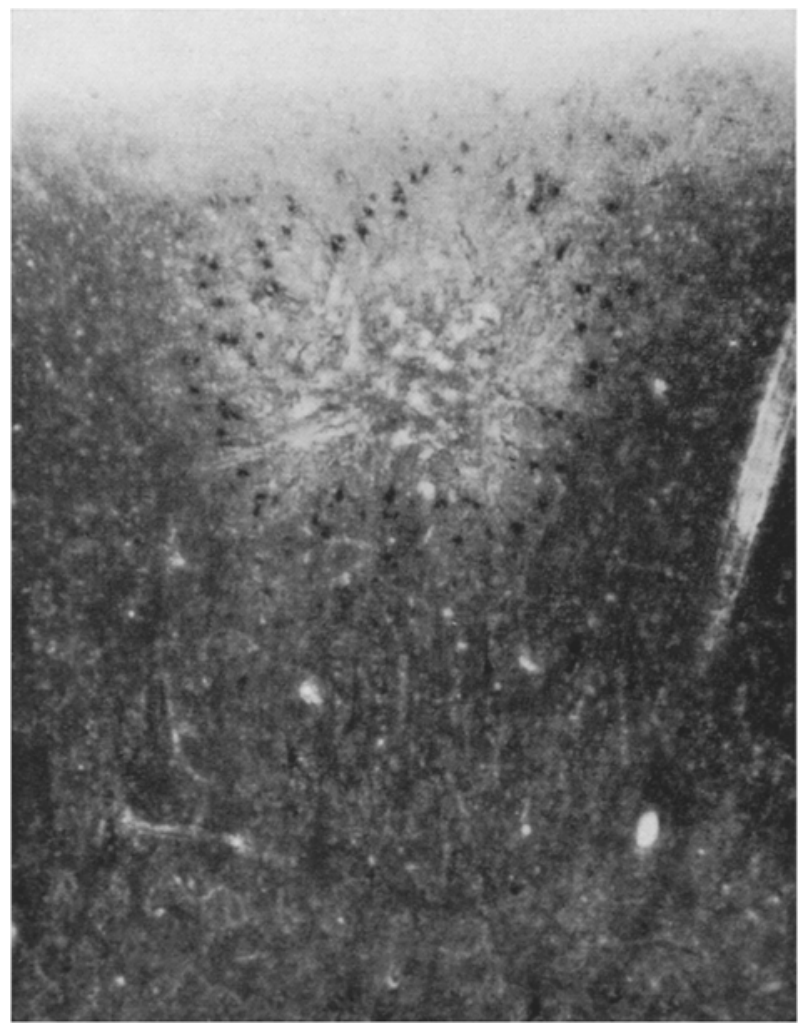

Fig. 4. Focal infarct in the cerebral cortex; note the loss of enzyme activity from the neuropil and the increased reaction in the hypertrophic astrocytes. DPN-diaphorase. $95 \times$

Hypertrophic astrocytes were also seen in cuffs of persisting tissue around some of the larger blood vessels. In contrast, the macrophages in the defective necrotic tissue showed a weak reaction, if any.

The enzyme activity in hypertrophic astrocytes decreased gradually with the distance from the necrosis (Fig.2). Infarcts in gray or white matter showed the same type of astrocytic reaction. In gray matter, hypertrophic astrocytes were clearly distinguishable from the neuropil, partıcularly if the reaction in the latter was decreased (Fig.4). In white matter, hypertrophic astrocytes were distinguished by increased enzyme reaction while the oligodendroglia cells showed either no change or disappeared altogether.

Oxidative Enzymes and Fatty Degeneration. Counterstaining of enzyme histochemical preparations with Fettrot revealed a clear-cut inverse relationship 
between the deposition of neutral fat and activity of oxidative enzymes in cells (Fig.5). Strong oxidative enzyme activity and heavy deposition of fat excluded each other; intermediary stages showed reduced enzyme activity and some deposition of fat. Hypertrophic astrocytes, thus, never showed deposition of fat, while the macrophages in the necrotic tissue were loaded with fat droplets and

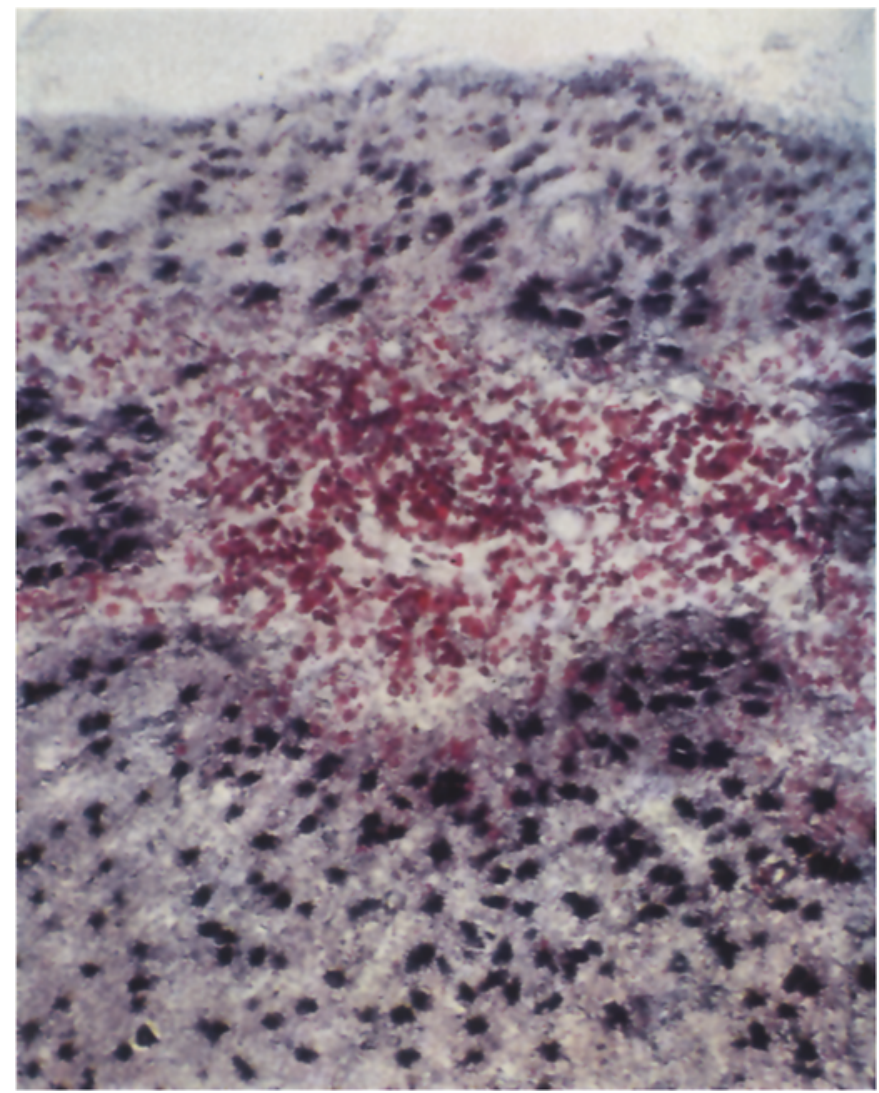

Fig. 5. Inverse relationship of oxidative enzymatic activity and deposition of fat. DPN-diaphorase counterstained with Fettrot. $110 \times$

showed no, or very little, activity of oxidative enzymes (Fig.5). Areas with deposits of fat droplets at some distance from the infarct, likewise, coincided with structures devoid of oxidative enzymatic activity.

Distribution of Mitochondria. Stains for mitochondria have been used for the comparison of the distribution of mitochondrial enzymes and mitochondria in normal and pathological tissue (FrIEde and PAX 1961; FrIede 1961). In the present material, many mitochondria were seen in portions of normal brain tissue showing strong enzyme reaction, while few were found in macrophages. Some difficulty was encountered in distinguishing mitochondria in hypertrophic astrocytes, because of a diffuse staining of their cytoplasm. Under favourable conditions though, numerous mitochondria were distinguishable in the cytoplasm; this observation was in accordance with electron microscopical observations (LUSE 1958). 
Distribution of Acid Phosphatase. The distribution of acid phosphatase in pathological tissue differed strikingly from that of oxidative enzymes; it paralleled closely the distribution of microglia. A strong reaction for acid phosphatase was seen in numerous cells scattered in the tissue bordering the necrosis. These cells, as demonstrated by the enzyme reaction, often showed a rod-shaped cell body with polar processes, suggestive of microglia cells; their distribution, size and shape differed clearly from that of hypertrophic astrocytes, toward and within the area of necrosis, the cells with acid phosphatase activity enlarged gradually,

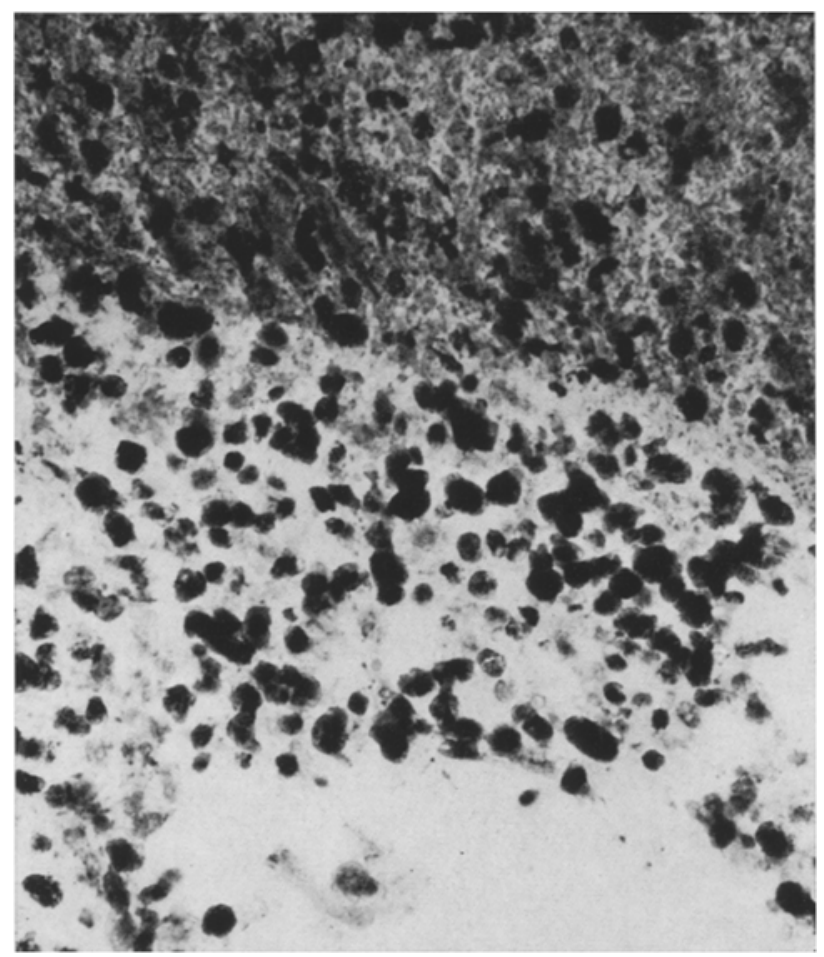

Fig. 6. Acid phosphatase activity in spherical macrophages within a tissue defect. $170 \times$

losing their processes, and forming typical gitter cells (Fig.6). There was no inverse relationship between the deposition of fat and acid phosphatase activity. On the contrary, the fatloaded necrotic regions, which had little reaction for oxidative enzymes, were heavily stained by the reaction for acid phosphatase, due to the strong reaction in the macrophages (Fig.6). Microglia cells in the adjacent tissue likewise showed strong activity of acid phosphatase in contrast to the cytoplasm of hypertrophic astrocytes which showed only weak staining. Reactions for oxidative enzymes, on the other hand, were strong in the astrocytes, but did not permit a clear-cut distinction of the microglia. The correlation of acid phosphatase activity and microglia was facilitated by comparison with silver impregnations.

Alkaline Phosphatase. Alkaline phosphatase activity in cerebral cortex was normally found in the walls of capillaries, in the tissue adjacent to the capillaries, 
and in the superficial portion of the molecular layer. The enzyme distribution in capillaries changed little in complete tissue necrosis. Isolated capillaries with strong alkaline phosphatase activity were observed in the defect (Fig. 7). The molecular layer covering necrotic portions of the cortex showed a marked increase of alkaline phosphatase (Fig.7) which was distinguishable macroscopically as a dark line on the surface of the cortex, sharply demarcating the necrotic

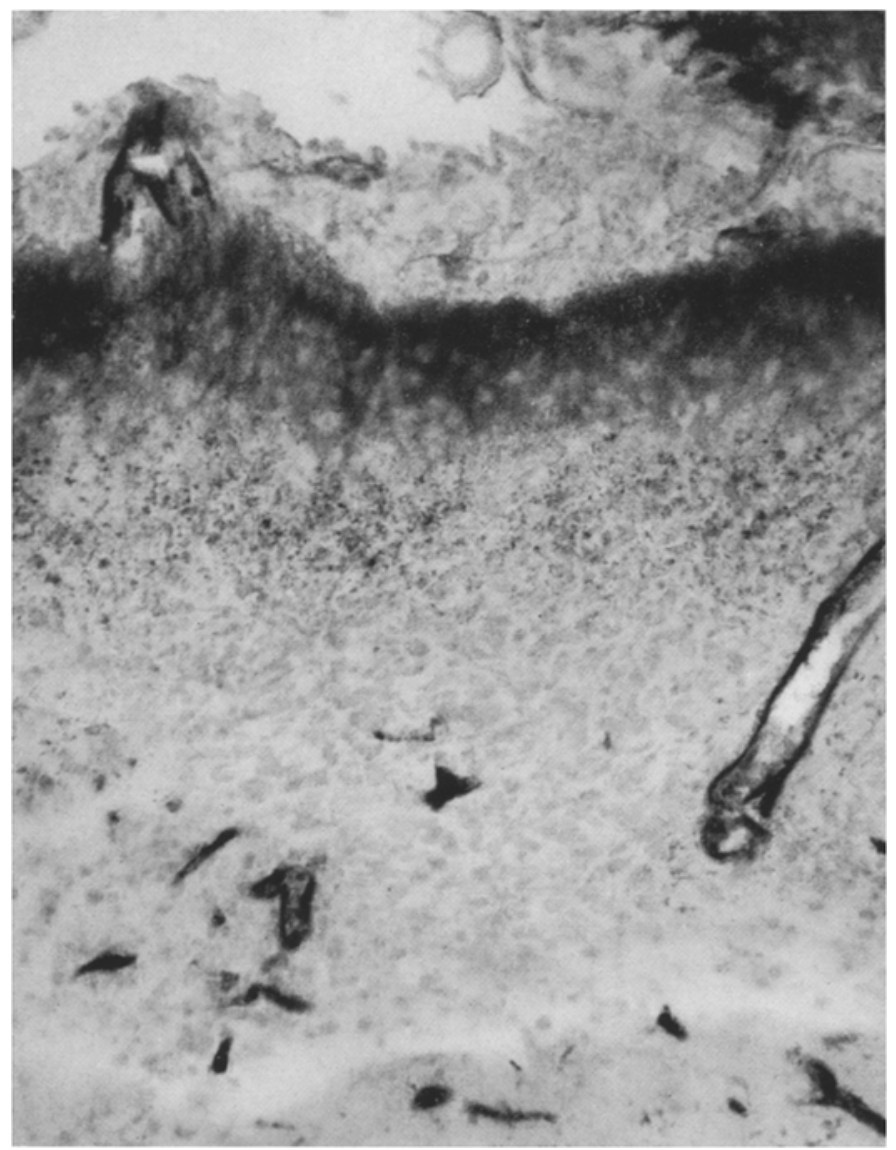

Fig. 7. Increased activity of alkaline phosphatase in the molecular layer covering an infarct; strong reaction in capillaries; absence of activity in macrophages. $80 \times$

regions. Microscopically, the reaction was distributed homogeneously in the tissue and cytological localization was not possible. It was interesting to note that alkaline phosphatase in brain tissue was always found where there were footplates of astrocytes.

Interrupted Axons in White Matter. Infarcts of white matter interrupt the axons of the affected fiber tracts; accordingly, silver stains often showed the typical damming and swelling of interrupted axons (CAJAL 1928). Experimental histochemical studies of axonal reaction showed, in such swollen axons, greatly increased activity of several oxidative enzymes (FrIEDE 1959). Similar observations were made in white matter bordering infarcts. Sections cut parallel to the 
course of tracts revealed the typical club-shaped terminal swellings of axons with strong activity of oxidative enzymes. Sections cutting axons at random, showed the transected swellings as large spherical or ovoid bodies with a strong enzyme reaction.

Neuronophagia. Neuronophagias were readily recognized in regions where activity of oxidative enzymes normally predominated in the perikarya of nerve

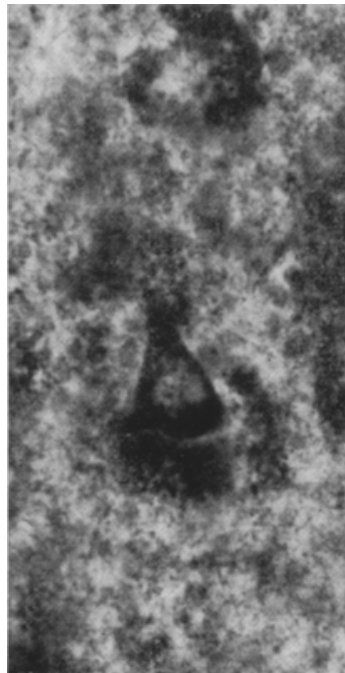

Fig. 8

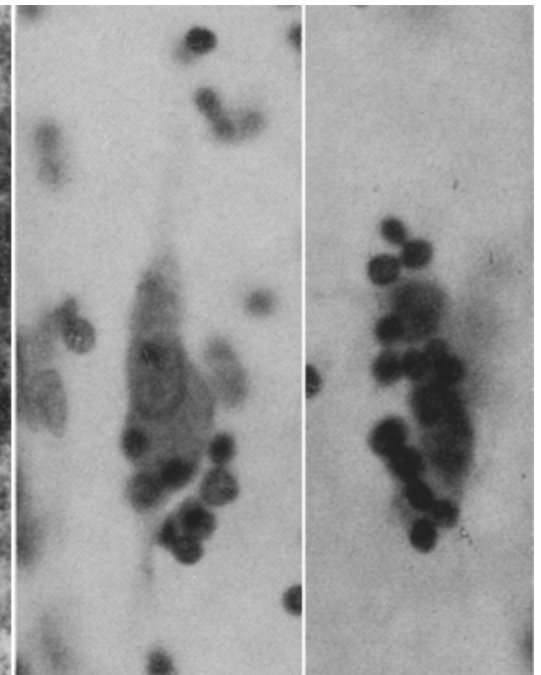

Fig. 9

Fig. 8 and 9. Neuronophagia. Fig. 8: DPN-diaphorase; the glia cells from an irregular "cloud" of enzyme activity around the nerve cell $315 \times$. Fig. $9:$ Nerve cells from the same region with chrom alum gallocyanin. $500 \times$

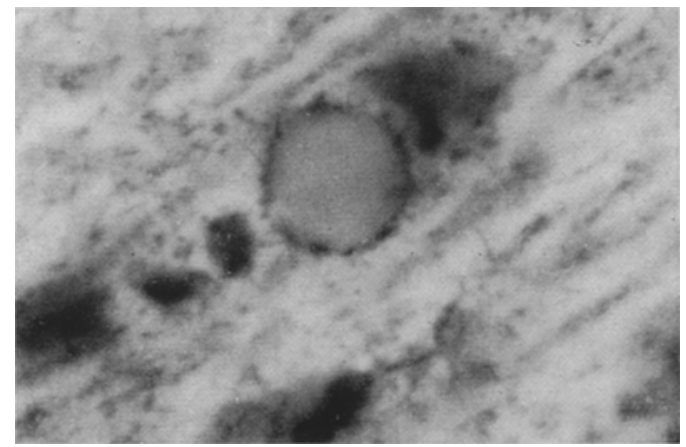

Fig. 10. Corpus anylaceum outlined by some DPN-diaphorase activity at its surface. $560 \times$ cells, but was low in the neuropil. In such regions, neuronophagias were identified as "cloudy" spots of increased activity of oxidative enzymes (Fig. 8). Individual perikarya of glia cells were not distinguishable, but the perikarya of the nerve cells sometimes were discernible from the activity in the surrounding clusters of glia cells. Comparison with adjacent conventional sections and counterstaining of the enzyme

reaction with chrom alum-gallocyanin proved that the areas of increased enzyme activity represented clusters of "neuronophagic" glia cells surrounding the nerve cells (Fig.9). These observations were in keeping with the data of RoIzIN (1951) demonstrating strong activity of cytochrome oxidase in neuronophagias. Neuronophagias were not distinguishable by acid phosphatase activity in the glia cells.

Corpora Amylacea. Corpora amylacea did not exhibit activity of any of the enzymes investigated; however, the surface of the corpora amylacea sometimes showed some DPN-diaphorase activity (Fig. 10). The presence or absence of such 
a reaction depended on the extent of enzyme activity in the surrounding tissue. Corpora amylacea in the subpial tissue of the spinal cord, for example, (where normally little oxidative enzyme activity was present) did not exhibit any reaction at their surface. Therefore, activity at the surface could not be considered a characteristic feature of corpora amylacea.

Hyaline Change of Arteries. Arteries with hyaline degeneration of their wall were characterized by a complete loss of all the enzymes studied.

\section{B. Pathogenesis of Perivascular Scars}

Absence of Capillaries in the Peri-Arterial Region. The normal vascularization of the peri-arterial brain tissue seemed to represent a key for the understanding of the pathogenesis of the periarterial scar formations in arteriosclerotic brains.

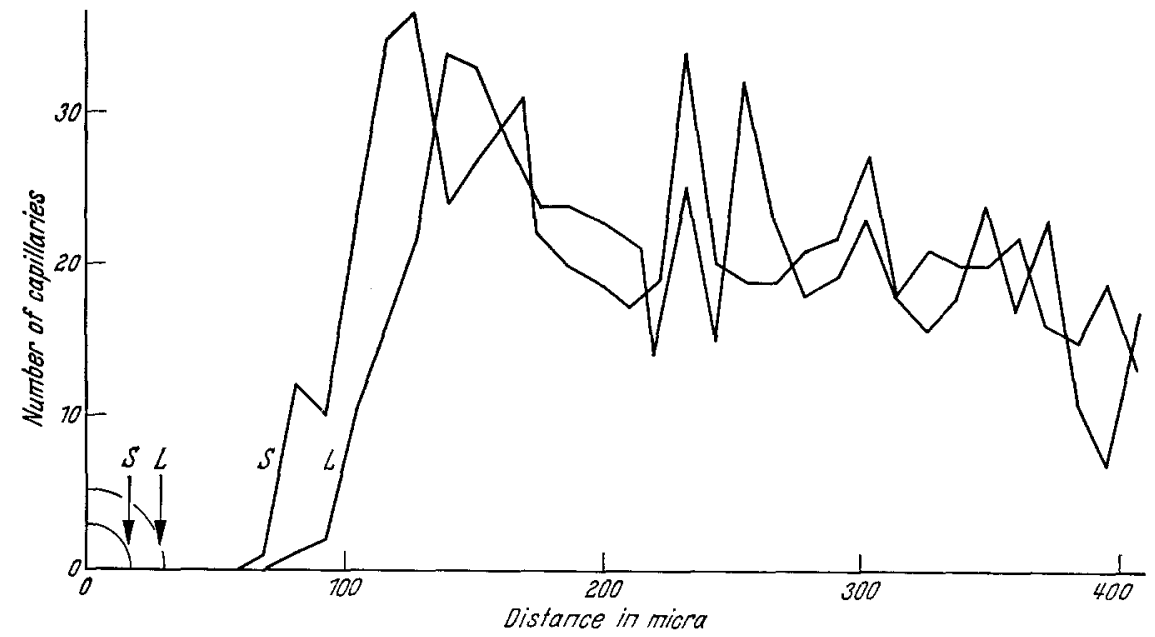

Fig. 11. Number of capillaries (vertical scale) as compared with the distance from the center of the artery. The curves represent data for small $(S)$ and large $(L)$ arteries. The presence of a capillary-free periarterial space is evident; for further discussion see text

PFEIFFER (1930) drew attention to the absence of capillaries in the tissue surrounding cerebral arteries. Pfeiffer's observations were substantiated by counts of the capillary density related to the distance from artery in india-ink injected cat brains. The counts were made in the cerebral cortex, but the periarterial absence of capillaries was observed everywhere in the brain. Fig. 11 evidences the absence of capillarization in the periarterial tissue, comparing counts for small $(S)$ and large $(L)$ arteries selected from the total material. Zero position on the horizontal scale marked the center of the artery and the arrows marked the position of the arterial wall. The absence of capillaries in the periarterial tissue was clearly visible. Since the arteries were filled with india ink and the sections embedded in glycerin-gel, there was only minimal, if any, shrinkage and dilatation of the spaces of Virchow-Robin; the capillary-free area thus truly reflected periarterial tissue. Comparison of large $(L)$ and small $(S)$ arteries evidenced a fairly uniform distance, from the arterial wall, of tissue without capillaries. At greater distance from the artery, the capillary density decreased due to interference with the periarterial tissue of other arteries. 
Two alternative hypotheses could explain the absence of capillaries in periarterial tissue: 1. A low metabolic rate of the periarterial tissue could render capillarization not necessary. 2. The artery, despite the thickness of its wall, could provide a satisfactory supply of oxygen and metabolites to the adjacent tissue, thus taking the place of capillaries. These alternative hypotheses could be judged on the basis of histochemical data on the periarterial tissue.

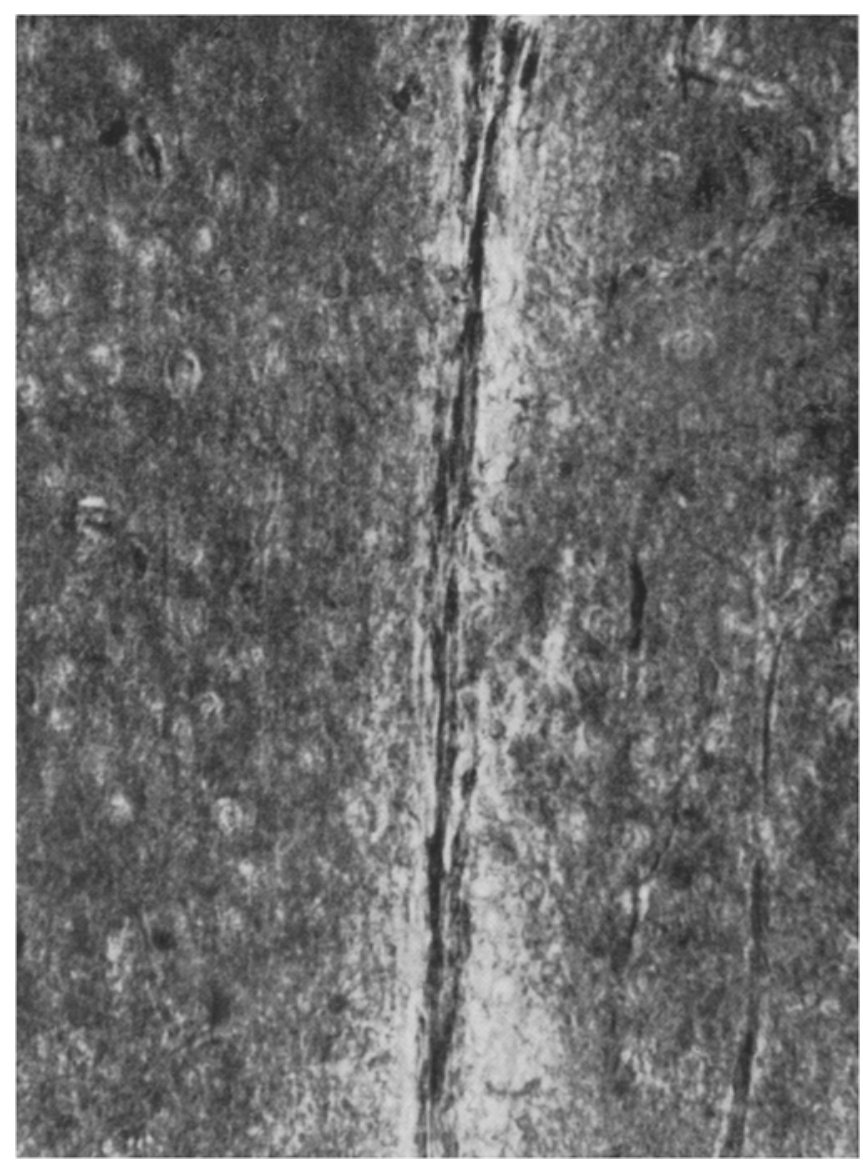

Fig. 12. Loss of enzyme activity in the periarterial tissue (neuropil) in arteriosclerosis (cerebral cortex). $180 \times$

Histochemistry of the Periarterial Tissue. The distribution of oxidative enzymes provides a fairly reliable parameter of the local average oxidative energy metabolism; this was indicated by the almost ideal correlation between capillarization and gradations of oxidative enzymes: Measurements in 35 nuclei of the cat brain stem showed a correlation coefficient of 0.88 between capillarization and succinic dehydrogenase activity (FRIEDE and FLemrng 1962). The distribution of oxidative enzymes in the periarterial tissue, therefore, was studied systematically in the various nuclei of the human brain. In all regions studied, oxidative enzyme activity in the neuropil did not change with the distance from the arterial wall. Nerve cells with a strong enzyme reaction, equalling the reaction of the rest of 
the cell population, often were intimately attached to the membrane lining the space of Virchow-Robin.

These observations definitely favoured the second hypothesis which claimed that the arteries, despite their thick wall, provided a sufficient supply of oxygen and metabolites to the adjacent tissue, thus rendering capillaries superfluous.

Histochemistry of the Periarterial Tissue in Arteriosclerotic Brains. Brains with cerebral arteriosclerosis showed a pathological decrease of the activity of oxidative enzymes in the periarterial tissue, particularly in the basal ganglia and the deep white matter but also in cerebral cortex. In white matter, the normal enzyme reaction of oligodendroglia cells disappeared; in gray matter, the periarterial tissue showed a loss, or a marked decrease, of the enzyme activity in the neuropil (Fig. 12). The nerve cells with strong enzyme activity disappeared from the periarterial tissue. These enzyme changes induced the formation of the typical perivascular glial scars (etat crible), which represent a common feature of cerebral arteriosclerosis.

This data suggested that one of the earliest changes in cerebral arteriosclecosis seemed to be an impairment of transport through the arterial wall; resulting in an insufficient nutrition and thus damage of the periarterial tissue. The distant tissue, which derived its supply from capillaries, was unharmed. Insufficient nutrition of the periarterial tissue probably would damage the tissue structures first which normally showed strongest activity of oxidative enzymes; accordingly, nerve cells, neuropil and oligodendroglia disappeared, resulting in formation of a periarterial scar. It was interesting to note that the walls of arteries with periarterial loss of enzyme activity usually did not show the enzyme changes accompanying hyalinosis (see above). This seemed to stress the significance of some unknown mechanism of transport through the arterial wall, probably one of the earliest functions impaired in arteriosclerosis.

\section{Diseussion}

The typical increase of oxidative enzyme activity in hypertrophic astrocytes described above has been observed in this laboratory in cases of multiple sclerosis, Alzheimer's disease, and in tissue adjacent to brain tumors (FRIED 1958). The association of acid phosphatase with microglia likewise was observed. Our observations were in agreement with the experimental histochemical findings in selective neuronal necrosis of rat brain (CoLMANT 1961) and with data from a more complete histochemical analysis of the enzyme changes in reactive astrocytes by Rubinstein, Kratzo and Mrquel 1961.

Another interesting feature was the inverse relationship between fatty degeneration and oxidative enzyme activity. This inverse relationship was consistent in neuropathological material as well as in other organs, such as in experimental fatty degeneration of the liver (FrIEde 1960). The most logical interpretation of this phenomena was that impairment of the oxidative Krebs cycle resulted in the deviation into fat synthesis of metabolites normally burned by the Krebs cycle. The time-honored concept of incorporation of fat in phagocytes, removing necrotic tissue appears to be in need of revision. The deposition of fat in these cells probably indicates a damaged citric acid cycle (and impaired 
oxidative metabolism) rather than the phagocytosis of fat from the tissue. This concept received strong support from experimental studies of fatty degeneration in tissue culture pursued at present in this laboratory: The data available confirm that there is a correlation between oxidative enzyme activity and fatty degeneration under conditions where removal of necrotic tissue was practically eliminated.

The spotted decrease of oxidative enzyme activity in the neuropil in regions of incomplete tissue necrosis represents another remarkable pathological change. Experimental studies showed that enzyme activity in the neuropil of the cerebral cortex may be decreased locally more than $50 \%$, while the nerve cells in these regions showed no changes if stained with conventional techniques (FRIEDE 1962). Conventional techniques, demonstrating the cell bodies, thus, may fail to show extensive pathological alterations of the cell processes in the neuropil, at least during the earlier phases of the pathological process. Since enzyme activity prevails in the neuropil in many, but not all, nuclei of the brain, the information obtained by conventional techniques may present a distorted picture.

The most logical interpretation of strong activity of oxidative enzymes but absent capillarization in the periarterial tissue seemed to be that the arterial wall, despite its thickness, provided sufficient nutrition for the periarterial tissue. It was not clear whether this was accomplished by active transportation of substances through the arterial wall, or whether the arterial wall had little resistance to the passive diffusion of substances through it. In any event, impairment of the transport through the arterial wall appeared to be one of the early changes of cerebral arteriosclerosis; this probably represented the mechanism responsible for the formation of periarterial scars.

\section{Summary}

The distribution of two oxidative enzymes (DPN-diaphorase and succinic dehydrogenase), two hydrolytic enzymes (acid and alkaline phosphatase) and data on mitochondria were described as to their relationship to the histopathology of cerebral arteriosclerosis. Incomplete necrosis of gray matter was characterized by a patchy, irregular decrease of oxidative enzyme activity in the neuropil. Complete necrosis (infarcts) showed a loss of enzyme activity in the tissue except the walls of capillaries which still showed activity of oxidative enzymes and also alkaline phosphatase. Hypertrophic astrocytes in the adjacent tissue were characterized by excessive increase of oxidative enzyme activity. Microglia showed little oxidative enzyme activity but strong activity of acid phosphatase. Fatty degeneration of cells was consistently accompanied by decreased oxidative enzyme activity; there was no such inverse relationship for acid phosphatase.

Study of capillarization, normal histochemistry, and of pathological changes of the periarterial tissue suggested that the wall of thick arteries normally provided sufficient nutrition of the periarterial tissue. Impairment of this function in arteriosclerosis was considered responsible for the formation of periarterial scars in arteriosclerosis.

\section{Zusammenfassung}

Die Verteilung zweier oxydativer Enzyme (DPN-Diaphorase und SuccinoDehydrogenase), zweier hydrolytischer Enzyme (saure und alkalische Phosphatase) und Befunde über Mitochondrien werden in ihrem Verhältnis zur Histo- 
pathologie der cerebralen Arteriosklerose beschrieben. Unvollständige Nekrosen der grauen Substanz waren gekennzeichnet durch stellenweise auftretende, unregelmäBige Verminderung der Aktivität oxydativer Enzyme im Neuropil. Vollständige Nekrosen (Infarkte) wiesen einen Verlust der Enzymaktivität im Gewebe auf, mit Ausnahme der Capillarwände, in denen noch Aktivität der oxydativen Enzyme und auch der alkalischen Phosphatase vorhanden war. Hypertrophische Astrocyten im angrenzenden Gewebe waren charakterisiert durch übermäßige Erhöhung der Aktivität der oxydativen Enzyme. Die Mikroglia zeigte nur geringe Aktivität der oxydativen Enzyme, jedoch starke Aktivität der sauern Phosphatase. Gleichzeitig mit der Zellverfettung kam es immer zu einer Aktivitätsverminderung der oxydativen Enzyme; für die saure Phosphatase konnte kein derartiges reziprokes Verhältnis nachgewiesen werden.

Untersuchungen der Capillarisierung, der normalen Histochemie und der pathologischen Veränderungen des periarteriellen Gewebes ließen die Annahme gerechtfertigt erscheinen, daß unter normalen Verhältnissen die Wände der dicken Arterien das periarterielle Gewebe genügend mit Nährstoffen versorgen. Eine Störung dieser Funktion bei der Arteriosklerose wurde als Grund für die Entstehung periarterieller Narben bei dieser Krankheit angesehen.

\section{References}

CAJAL, S. R.: Degeneration and regeneration of the nervous system. London: Milford 1928.

Colmart, H. J.: Histochemical detection of various enzymes in selective neuronal necrosis of rat brain. IV. International Congress of Neuropathology. München: September 1961.

Farber, E., W. H. Sternberg and C. E. Dunlap: Histochemical localization of specific oxidative enzymes. J. Histochem. Cytochem. 4, 254-284 (1956).

FrIede, R. L.: Histochemischer Nachweis von Succinodehydrogenase in Biopsien von menschlichem Hirngewebe. Virchows Arch. path. Anat. 332, 216-223 (1958).

-, Transport of oxidative enzymes in nerve fibers. A histochemical investigation of the regenerative cycle in neurons. Exp. Neurol. 1, $441-466$ (1959).

--, Inverse distribution of fat and oxidative enzymes in fatty livers produced by carbon tetrachloride. J. Path. Bact. 79, 109-113 (1960).

-, A histochemical atlas of tissue oxidation in the brain stem of the cat. New York u. Basel: Karger 1961.

--, Histochemical studies in multiple sclerosis. A.M.A. Arch. Neurol. Psychiat. 5, 433-443 (1961).

-, A histochemical study of DPN-diaphorase in human white matter; with some notes on myelination. J. Neurochem. 8, 17-30 (1961).

-, The cytochemistry of normal and reactive astrocytes. J. Neuropath. exp. Neurol. (in print) (1962).

-, Correlations between the EEG and cortical histochemical changes in experimental brain lesions. Exp. Neurol. 5, 89-99 (1962).

-, and L. M. FleMrNG: A mapping of oxidative enzymes in the human brain. J. Neurochem. 9, 179-198 (1962).

-, and K. R. MAGEE: Alzheimer's disease-presentation of a case with pathologic and enzyme histochemical observations. Neurology (Minneap.) 12, 213-222 (1962).

-, and R. H. PAX: Mitochondria and mitochondrial enzymes; a comparative study of localization in the cat's brain stem. Histochem. 2, 186-191 (1961).

LUSE, S.: The ultrastructure of normal and reactive astrocytes. Lab. Invest. 7, 401 (1958). 
72 Retnhard L. Friede: An enzyme histochemical study of cerebral arteriosclerosis

Nachlass, M. M., K.-C. Tsou, E. de Souza, C.-S. Cheng and A. M. Seligman: Cytochemical demonstration of succinic dehydrogenase by the use of a new P-Nitrophenyl substituted ditetrazole. J. Histochem. Cytochem. 5, 420-436 (1957).

Novellt, A.: Rapid staining of mitochondria. Experientia (Basel) 15, 274-280 (1959).

Pfetrfer, R. A.: Grundlegende Untersuchungen für die Angioarchitektonik des menschlichen Gehirns. Berlin: Springer 1930.

RotzIN, L.: Comparative morphologic and histometabolic studies of nerve cells in brain biopsies and operations. J. Neuropath. exp. Neurol. 10, 177-189 (1951).

Rubinsteta, L. J., I. KLatzo and J. Mrquel: Oxidative enzyme activity of glial cell in experimental cortical injury in the cat. IV. International Congress of Neuropathology. München: September 1961, and J. Neuropath. exp. Neurol. 21, 116-136 (1961).

SCARPElli, D. G., R. Hess and A. G. E. Pearse: The cytochemical localization of oxidative enzymes: I. Diphosphopyridine nucleotide diaphorase and triphosphopyridine nucleotide diaphorase. J. biophys. biochem. Cytol. 4, 747--752 (1958).

Reinhard L. Friede, M.D.

Mental Health Research Institute, The University of Michigan, Ann Arbor, Michigan, U.S.A. 